\title{
Aesthetic Analysis on Line Art in Chinese Painting Art
}

\author{
Yuanming Zhang \\ Zhuhai College \\ Jilin University \\ Zhuhai, China
}

\begin{abstract}
This paper describes line's representation and expression function in Chinese painting art, points out the charm of line application in Chinese painting art, meticulously discusses aesthetic standard of line art in Chinese painting art from three aspects: vividness, artistic conception and interestingness, analyzes expressive force of line art in Chinese painting art from the perspective of figure painting, landscape painting and birdand-flower painting, and conducts an overall analysis on artistic appreciation of line in Chinese painting art.
\end{abstract}

Keywords-Chinese painting; art; line art; aesthetic appreciation; analysis

\section{INTRODUCTION}

Aesthetic nature of line in Chinese art originates from calligraphy. In the Eastern Han Dynasty, Chinese character has developed beyond its utility function and into aesthetic form in art field. Besides aesthetic research on word-forming structure, another important aspect is aesthetic analysis on lines. Since the Southern Dynasties when Wang Wei discovers that calligraphy and Chinese painting are interlinked in aesthetic appreciation of form, based on calligraphy line aesthetic appreciation, line in Chinese painting has formed its own unique aesthetic features. Lines in Chinese painting art can not only shape figures, flowers, birds, landscape and other specific modelings, but also convey the painter's emotion and willing. Appropriate lines should be chosen in the process of using lines because different lines bring people different feelings. Line application is very charming, not only in vigor of strokes, but also in feelings of rhythm, rhyme, speed, force and emotion. This paper intends to analyze aesthetic appreciation of line art from multiple perspectives as follows.

\section{FUnCtion OF Line ART In Chinese PAINTING ART}

\section{A. The Core of Chinese Painting 'S Modeling}

In western countries, the basis of painting is the technique of sketch, which can create the effect of actual texture through shaping sense of volume and space. Chinese painting expresses different artistic conceptions through pen and ink and emphasizes on expressing personal emotion and conveying personal will. Therefore, line becomes a basic component of Chinese painting and adds biotic images to Chinese painting, becoming a necessary painting means of Chinese painting. For example, Zhu Qizhan creates vigorous and efficient iron-silver hook-type lines, Fu Zhongqi creates decoratively beautiful lines which can convey emotional ties with the countryside, $\mathrm{Wu}$ Guanzhong creates long lines with rhythm beauty and detached dots, Zhou Shaohua creates lines which are mixed together with the plane and colors to demonstrate overall effect of the plane, and Huang Zhou creates a kind of wide line which has vigor beauty and is similar to the plane. Creation of these lines reflects Chinese painting's artistic conception and lyric effect to a great extent.

In Tang Dynasty, Zhang Yanyuan says: "The most important point in object painting is similarity in appearance, in order to achieve which, the painter has to draw the object's physique and spirit. The key is the technique of brushwork." He describes the important function of lines in Chinese painting in an extremely clear way. Line is an important medium in Chinese painting's modeling, like human body's skeleton supporting the whole body structure. Therefore, lines directly influence the lyric and aesthetic feeling painting works convey to people. Lines in different forms demonstrate different characters and give people different emotional feelings. For example, oblique line, horizontal line and vertical line convey direct, clear and vigorous traits of character to people and make them feel capable and experienced musculinity. Vertical lines make people feel lofty, like spires, peaks and big trees, but they make people feel cold and lonely at the same time. Waterfall and rain can also make people feel vigorous. Horizontal lines in rows give people static and peaceful feelings; oblique line is very dynamic and skew curves give people vivacious and unstable character feelings. Compared with curves, radioactive lines give people a feeling of volcanic strength; curves and free lines are elastic with soft imagination, bringing people a kind of elegant and vivacious feeling. We can know what the painter is thinking about through lines. For example, in Wu Guanzhong's Chinese Wistaria, wistaria intertwine with each other and this kind of intertwined criss-cross gives people a feeling of kind, enmity, love and animosity.

\section{B. Bearing the Painter's Emotion and Aesthetic Taste}

Lines in Chinese painting are not totally attached to objects. Seeing from the perspective of presentation, lines in Chinese painting are used to shape the body. Analyzing from the perspective of expression, lines convey the painter's thought and bear the painter's emotion. Since lines in Chinese painting originate from calligraphy, painters also demonstrate 
handwriting effects and stippling rhythms of calligraphy in the process of using lines. In the process of presenting objective targets, as the creation subject, most of painter's lines experience personal processing and are subjective. These lines' rich changes transform objective images into subjective images. Different pen methods create different visual effects and express different subjective feelings. Smooth and fluent lines generally represent a happy mood and even the turning point is mellow. Paused and astringent lines represent worry and melancholy. This saying adopts personification of lines. Painters use changeful lines to demonstrate the depicted objective image, express their understanding and feeling about the image, and then express their thought and place their emotion in the painting.

Lines not only bear painters' emotion, but also reflect their personal aesthetic taste. During the process of painting expression, lines with subjective emotion combine with each other to produce a visual effect with a sense of beauty, expressing painters' feelings, spiritual realm and aesthetic taste. For example, in Shi Tao's "One Stroke Theory", "One Stroke" refers to a line which is drawn to present the object. From this line, we can feel the relation between "heart, law, doctrine and object". One stroke leads ten thousand strokes and ten thousand strokes unite as one. It is an aesthetic theory which starts from true personal disposition and combines "reason and law, doctrine and art, and object and I". Zong Baihua says "Through chirography of this stroke, the beauty of every phenomenon outflows, namely human's inner beauty. Beauty can't not be felt, drawn or demonstrated without human. Painters, calligraphers and sculptors create this line to present every phenomenon in a free way, in which lies the beauty." [1]

\section{AESTHETIC EMBODIMENT OF LINES IN CHINESE PAINTING ART}

The essence of Chinese painting lies in lines, which can convey the whole structural framework of images, making it a way for painters to convey emotion and subjective consciousness. Line is the most inclusive and simplest language expression form of art in Chinese painting, manifesting the power of morality, spirit and personality. Line's charm not only lies in its extraordinary stroke force, but also lies in bringing the feeling of rhythm, rhyme, speed, strength and emotion to people. Specifically, we come down to two aspects. One is each line's rhyme and rhythm and the other one is the rhyme and rhythm between the entirety of the painting and lines in the painting.

Rhythm conveys lines' strength and law while rhyme conveys fluctuate changes of painter's emotion, which is a kind of mental course or track. In the process of using lines, the holistic keynote of Chinese painting is average and forceful. Based on it, changes are made through drawing the line quickly or slowly, and lightly or heavily, lifting or pressing the paintbrush, making a turn and so on according to the emotion painters want to convey, thus endowing lines with a sense of beauty of rhyme and rhythm. Based on lines which differ in length, width, complicated degree, density, intensity in color, compacting degree, empty and full, intervein, expectation and echoing, the whole painting's beauty of rhyme and rhythm is presented vividly. During the process of using lines, calligraphy is brought into Chinese painting. To some degree, official script, seal script, cursive script and regular script are brought into Chinese paintings. Many painters take much account of lines' characteristic features in writing and are particular about lines' emotion, temperament, speed and strength.

Lines applied in Chinese painting also possess decorative beauty. In the whole painting, people care the most about lines' harmonious arrangement and application. Vague, abstract and scrambled images are presented in a more specific, regular and logical way through application of a series of related technique patterns. Therefore, beauty of lines appears as a kind of highly comprehensive, clear and refined programmed language. Compared with western painting, Chinese painting has different conceptions of realistic painting and freehand brushwork. The major feature of western painting is conveying painters' emotion and shaping figures' image through application of lines. But, during the expression process, it places extra emphasis on expressing the sense of space, quality and texture. The line itself has no independent existence value and it is a part of light and shade, structure, form and other contents to express. In Chinese paintings, lines are much more important than shaping the form and they are used to express painters' idea, emotion and thought, acting as a means to convey the painter's idea and thought.

Beauty of lines has an important status in the whole history of Chinese painting, giving people a feeling of alive and everlasting. It gives people a kind of elegant and noble feeling in spirit and nice ideas and images. Techniques of Chinese painting are demonstrated vividly through lines, which are pure and beautiful with extremely strong penetrating power and implications. All Chinese painters should pay special attention to application of lines, because it is an indispensable means to shape the modeling in Chinese painting. Thus, attention should be attached here.

\section{AESTHETICAL STANDARD OF LINE ART IN CHINESE PAINTING ART}

\section{A. Lines Need To Have Vivid Portrayal}

The character "Shen" has two meanings. One meaning is "Shen" of the painted object, referring to depicting the object's features on the basis of vividness. Another meaning is "Shen" of creation subject, referring to expression of the painter's spiritual outlook. In order to achieve the above two goals, lines used in the painter's creation process should meet the following requirements: First, lines should have subjectivity. As the creation subject, painters need to subjectively process lines. Subjectivity is used here in comparison with passive depiction of objective target. Only by surpassing imitation of objective images and expressing the creation subject's consciousness and spirit through exaggeration, transformation, material implication and other techniques, can appreciators feel the inner Shen of things and creators through exterior lines. Second, in order to meet the requirement of vivid portrayal for lines, lines should bear freehand brushwork. Freehand brushwork is a term in comparison with realistic painting. Western painting is mainly about realistic painting, trying to vividly show up the image's external details and internal 
structural relations. Freehand brushwork refers to summarizing and abstracting depicted objects. Lines in freehand brushwork surpass images with objective existence. Here, we take expression of a graceful line of clothing as an example. Expression of freehand brushwork first needs summarization. Select the most representative clothing line which plays a leading role to demonstrate. Reduce the quantity, improve accuracy of the line, and intensify the elegant feeling of this line. All these above efforts aim to achieve superficial freehand brushwork. There is no need for internal freehand lines to pay attention to details of objects and the line is drawn to express the painter's feeling after seeing lines of clothes. Before drawing, the painter has emotionally and spiritually processed the objective target. Zhu Da's works are famous for their extremely simple freehand brushwork. Extremely simple and essential lines are used to demonstrate complex things. Through observation of the nature and accumulation, the chick, bird, every tree and bush with only a few strokes under his brushwork can vividly express the feeling that the bird will fly away upon touching. Subtraction is used to perfection in his painting and it seems that his use of subtraction has entered the state of "Fat with an extra stroke and thin with less one stroke".

\section{B. Lines Need to Express the Sense of Artistic Conception}

Chinese painting is particular about "lively spirit and charm". Qi and Yun originally aren't painting vocabularies. With appearance of painting's aesthetic consciousness and injection of creation subject's living spirit into paintings, artistic conception becomes a standard to evaluate paintings. "Qi" reflects the whole painting's connotation and is represented as lines' movement momentum. "Yun" is the sorting and specification of Qi and represented as lines' sense of rhythm. Slow and quick drawing, turning, jerking and line combination with proper variable density bear the artistic conception of lines in Chinese painting. "Lines' rhyme, artistic conception and sense of rhythm are mainly reflected in lines' crisscross arrangement, twists and turns, jerking in favorable and adverse trends, force and speed. As to a single line, straight line seems quiet while curve or oblique line seems sportive. If lines can achieve rise and fall, quietness and movement, and softness and firmness alternatively, rhyme and sense of artistic conception come into being naturally." [2] The essence of artistic conception is to demonstrate a kind of living vigor which is determined by creation subject's inner spirit. Painting work's artistic conception originates from painter's personality charm and personal cultivation which are expressed through visual forms and personality characteristics of lines drawn by the painter.

\section{Lines Need Interestingness}

Line's interestingness refers to that line has clear personal and stylish features. On the basis of lively spirit and charm, lines with interestingness can demonstrate strong personality characteristics. Lines with interestingness are supported by a unique visual sense and their connotation feature is vividness. They give people the feeling of making sense and beyond expectations and add charm to artistic works. Works of four monks in the early Qing Dynasty have distinct interestingness. Zhu Da's works are simple and succinct, Shi Tao's are unusual, elegant and tasteful, Kun Can's are simple and elegant, and
Hong Ren's are profound, brief and quiet. Their own features of works are demonstrated through application of lines with interestingness in paintings.

\section{EXPRESSIVE FORCE OF LINE ART IN CHINESE PAINTING} ART

\section{A. Figure Painting}

In Chinese painting, there are mainly two ways to depict figures, namely freehand brushwork and fine brushwork. Figure painting with fine brushwork is also called line drawing which requires lines to be fine, smooth and orderly and requires combination and arrangement of lines. Through this method, character image is generally extremely vivid and lifelike and the modeling is also very vivid and beautiful, reflecting lines' unique charm. Figure painting with freehand brushwork is totally different from the painting with fine brushwork. Painter shapes the artistic image of figures in mind through imagination. Generally, lines are abstract and give people a feeling of bone and column modeling in shaping the figure, getting rid of abundant objective external constraints and conveying the figure's internal vitality and sense of beauty.

\section{B. Landscape Painting}

The greatest charm of landscape paintings lies in that they can not only show the beauty of our country's great rivers and mountains, but also convey the painter's life pursuit and spiritual realm vividly. The painter stands in front of our country's great rivers and mountains, appreciates our country's beautiful rivers and mountains and conveys personal inner emotion and personality charm through elegant and beautiful landscape works. Specifically speaking, lines in landscape paintings should have the following several features: First, they need to be forceful. It seems that the force demonstrated through lines is prominent on the paper and generates a sense of life with explosive force inside the painting. Even if very thin and soft lines should have force to penetrate the paper and show internal force. Second, lines should be fluent. Lines should be extremely fluent and continuous to demonstrate the movable life force. Last, lines should be accurate. It requires painters to ensure that once putting pen to paper, tangible lines come out. Namely, concrete object should appear upon falling of the brush. Every line should be fluent, succinct and profound without tedious and redundant feelings.

\section{Bird-And-Flower Painting}

The bird-and-flower painting here includes detailed depiction of animals and plants, and aerial birds and flowers. The bird-and-flower painting has three expression forms, namely freehand brushwork, fine brushwork and fine brushwork together with freehand brushwork. The bird-andflower painting can date back to primitive bronze, painted pottery and totem at the earliest and becomes very mature in Tang Dynasty. The painter conveys personal inner thought and emotion, shows social background and spiritual outlook of that times, and presents specific life styles and status of the society which the painter lives in and other relevant contents through detailed depiction of flowers, birds, animals and plants. The painter's inner emotion and soaring ambition are also depicted 
through lines, vividly expressing the painter's thoughts. It is meaningful and worth pondering.

\section{CONCLUSION}

Lines occupy an important status in Chinese painting, and can depict images of figures, landscape, flowers and birds that painters want to describe and deeply convey painters' thought and emotion. Lines in Chinese painting can show the era the painter lives in and its social background and convey the painter's ambition and emotion. Therefore, so to speak, line is an important artistic expression form of Chinese painting and its future development direction is becoming more vividness, conveying emotion, freehand brushwork and integration. Painters should research and refine lines profoundly and use lines to convey personal emotion and demonstrate Chinese painting's unique charm.

\section{REFERENCES}

[1] Zong Baihua. Strolling in Aesthetics[M]. Shanghai People's Publishing House.

[2] Luo Shiping. Line Sketch: Footstone of Chinese Painting Inheritance[J]. Art Research.

[3] Yu Xiaoyu. Research on Aesthetic Features of Line Art in Chinese Painting[J]. People's Tribune, 2015,33:32-33.

[4] Wei Jianming. Artistic Aesthetics of Lines in Chinese Painting[J]. Art Science and Technology, 2016,07:217.

[5] Liu Ke. Analysis on Aesthetic Value of Line Art in Chinese Painting[J]. Art Panorama, 2016,07:72-73.

[6] Wu Xiumei. Comparison between Chinese Ceramic Painting Art and Chinese Painting Art[J]. Hundred Schools in Art, 2013,02:196-199.

[7] Liu Fang. Analysis on Artistic Aesthetics of Chinese Painting and Western Oil Painting[J]. Art and Design(Theory), 2013,07:118-120.

[8] Xie Yiming. Aesthetic Value of Line Art in Traditional Chinese Painting[J]. Art Education, 2015,03:86.

[9] Chen Bingli. External Form and Internal Essence of Lines in Chinese Painting[J]. Traditional Chinese Painter, 2012,01:66-67. 